\title{
Foreword to the second edition
}

There are two major changes from the first edition. The discussion of non-finite clauses has been extended and is now in a separate chapter. A chapter on discourse and syntax, which was to have been included in the first edition, now finds a place. The chapter on aspect and voice has been revised to bring out the connections between these topics and the organisation of discourse. The chapter on case, gender and mood has gone. These are important topics but a chapter on discourse and syntax seemed more in demand. All the chapters have been shortened and tightened up. The text now emphasises the central role given to dependency relations, particularly in the definition and recognition of finite and non-finite clauses. This aspect of the book reflects my exposure to the work of John Lyons and John Anderson in Edinburgh in the late sixties and to Peter Matthews' Syntax (Cambridge University Press, 1981). 